\title{
High-efficiency catalytic degradation of phenol based on the peroxidase-like activity of cupric oxide nanoparticles
}

\author{
Y.-B. Feng $\cdot$ L. Hong $\cdot$ A.-L. Liu $\cdot$ W.-D. Chen $\cdot$ \\ G.-W. Li $\cdot$ W. Chen $\cdot$ X.-H. Xia
}

Received: 6 January 2013/Revised: 25 October 2013/Accepted: 20 November 2013/Published online: 10 December 2013

(C) Islamic Azad University (IAU) 2013

\begin{abstract}
Based on the recently discovered peroxidaselike activity, cupric oxide nanoparticles with diameters about $6 \mathrm{~nm}$ were synthesized and used to remove phenol from aqueous solution. As a kind of peroxidase mimetic substance, cupric oxide nanoparticles can be used as a promising catalyst for the total oxidation of phenol in aqueous solutions by peroxidation, which therefore avoids the need of secondary treatments. The mechanism study suggested that cupric oxide nanoparticles could catalyze hydrogen peroxide to form hydroxyl free radicals, which were mainly responsible for the removal of phenol. The catalytic conditions for the phenol degradation were extensively optimized among a range of $\mathrm{pH}$ as well as initial concentration of catalyst, $\mathrm{H}_{2} \mathrm{O}_{2}$ and phenol. High degradation efficiency of phenol can be achieved in relatively wide $\mathrm{pH}$ range from 3 to 7 . Under optimized conditions, phenol $(0.25 \mathrm{~g} / \mathrm{l})$ can be eliminated completely in $35 \mathrm{~min}$. It can be potentially applied in treating the industrial wastewaters.
\end{abstract}

Keywords Phenol - Degradation · Cupric oxide nanoparticles $\cdot$ Enzyme mimic $\cdot$ Catalysis

Y.-B. Feng · L. Hong · A.-L. Liu · W.-D. Chen ·

G.-W. Li - W. Chen $(\square)$

Department of Pharmaceutical Analysis, Fujian Medical

University, Fuzhou 350004, China

e-mail: chenandhu@163.com

X.-H. Xia

State Key Laboratory of Analytical Chemistry for Life Science,

School of Chemistry and Chemical Engineering, Nanjing

University, Nanjing 210093, China

\section{Introduction}

Industrial processes generate a large diversity of wastewater containing organic pollutants, which has become a major social and economic problem. Phenol is one of the major organic pollutants in aqueous effluents generated by various industrial processes, such as refineries, resins and plastics processing, coal conversion, and manufacture of petrochemicals. Due to its high toxicity and hard degradation, phenol has been listed as one of the priority control pollutants by the environmental protection agency in many countries. A variety of techniques such as solvent extraction (Li et al. 2004), physical adsorption (Burleigh et al. 2002; Dabrowski et al. 2005), pervaporation (Hoshi et al. 1997), wet air oxidation (Joglekar et al. 1991; Chen et al. 2001), ozonolysis (Chedeville et al. 2007), wet peroxide oxidation (Barrault et al. 2000; Kang et al. 2002; Calleja et al. 2005; Gonzalez et al. 2008), electrochemical oxidation ( $\mathrm{Li}$ et al. 2005; Pacheco et al. 2007), photocatalytic oxidation (Vione et al. 2005; Wang et al. 2005), supercritical water gasification (Dileo et al. 2007), electrical discharge degradation (Liu and Jiang 2005), and biodegradation (Jiang et al. 2006; Ucun et al. 2010) have been developed to remove phenol from industrial wastewaters. Each method has its own advantages and disadvantages and can be only applied in speculate conditions. Biological treatment is ideally for low concentration, typically around $50 \mathrm{ppm}$ or lower for phenol. In addition, biodegradation processes are inherently slow and do not allow for high degrees of removal. Diluting wastewater to a suitable concentration and the disposal of sludge formed during the biological treatment can pose additional expenses and environmental problems. One more promising process is catalytic wet oxidation, which destroys a variety of organic pollutants and achieves a high conversion with the addition of catalyst. 
Enzymes are promising candidates for catalysis and sensor owing to their chemo-, regio-, stereo-, and chiralspecificity as well as the mild reaction conditions that can be used (Schmid et al. 2001; Bornscheuer 2003; Schoemaker et al. 2003; Lu et al. 2011). In recent years, enzyme-catalyzed processes have been widely reported to play an important role in numerous waste treatment applications (Duran and Esposito 2000). Horseradish peroxidase is, by far, one of the most commonly used enzyme in waste treatment in order to remove phenols from aqueous solutions. In the presence of hydrogen peroxide, phenolic compounds are catalytically oxidized to phenoxy radicals and then polymerized to form insoluble high molecular weight polymers that could be easily removed by filtration or sedimentation (Klibanov et al. 1983). Such methods have several advantages due to their specificities and efficiencies. However, enzyme application was currently hampered by limited natural source, difficult and high-cost purification process, and inherent instability. In order to improve the active life of the enzyme, and thereby a reduction in treatment cost, various efforts have been devoted to find the alternative source, protecting reagent and immobilization method of enzyme on various supports (Cheng et al. 2006; Gonzalez et al. 2008).

Recently, the ferromagnetic nanoparticles have been found to be intrinsically active catalyst for oxidation reactions similar to that found in natural peroxidases (Gao et al. 2007). What is more, the peroxidase nanomimetics have a definite advantage compared with their protein-based counterparts because they are considerably more stable over a wide range of temperatures and various levels of acidity. Being inspired by the application of peroxidase, various nanomimetics, such as $\mathrm{Fe}_{3} \mathrm{O}_{4}$ nanoparticles (Zhang et al. 2008, 2009), gold nanoparticles (Han et al. 2008), iron oxide-based nanoparticles (Zelmanov and Semiat 2008), and $\gamma$-FeOOH nanosheets (Peng et al. 2011), have been used as catalysts for the catalytic oxidation of phenol. In the previous study, we have found that cupric oxide nanoparticle is a highly effective catalyst to peroxidase substrates, and the binding affinity for the substrate 3,3',5,5'-tetramethylbenzidine (TMB) is higher than that of HRP and other peroxidase nanomimics (Chen et al. 2011). Based on this finding, we studied in this work the potential application of cupric oxide nanoparticles in phenol removal. The experimental results show that this process is highly efficient as compared to that using other peroxidase nanomimics. Complete phenol degradation can be achieved within about 30 min under mild conditions. This research was carried out in 2012 at Fujian Medical University, China.

\section{Materials and methods}

Chemicals and materials

All reagents used in the experiment were of analytical reagent grade and used without further purification. Cupric acetate, sodium hydroxide, glacial acetic acid, phenol, 4-aminoantipyrine (4-AAP), potassium ferricyanide, and $30 \%(v / v) \mathrm{H}_{2} \mathrm{O}_{2}$ were purchased from Sinopharm Chemical Reagent Co. Ltd (Shanghai, China). HPLC-grade methanol was obtained from Fisher Scientific Corporation (Fair Lawn, NJ, USA). Other reagents and chemicals were at least analytical reagent grade. The water used was purified by a Milli-Q system (Millipore, USA).

Preparation and characterization of cupric oxide nanoparticles

The cupric oxide nanoparticles with a diameter of $6 \mathrm{~nm}$ were prepared via a previously reported quick precipitation method (Chen et al. 2012). Briefly, $150 \mathrm{ml}$ of $0.02 \mathrm{M}$ copper acetate aqueous solution was mixed with $0.5 \mathrm{ml}$ glacial acetic acid in a round-bottomed flask equipped with a refluxing device. The solution was heated to boiling with vigorous stirring. Then $10 \mathrm{ml}$ of $40 \mathrm{~g} / \mathrm{l} \mathrm{NaOH}$ aqueous solution was rapidly added into the above boiling solution, where a large amount of black precipitate was simultaneously produced. The precipitate was centrifuged, washed three times with absolute ethanol, and dried in air at room temperature. About $85 \mathrm{mg}$ cupric oxide nanoparticles can be obtained. The percentage of conversion of copper to cupric oxide nanoparticles is about $35 \%$.

The morphology and size distribution of the nanoparticles were studied by using a transmission electron microscope (TEM) of Tacnai-12 (Philip, Netherlands). The crystal phase was investigated by X'Pert Pro MPD X-ray diffractometer (Panalytical, Netherlands). As reported in our previous work, the average particle diameter is found to be approximately $6.3 \mathrm{~nm}$, and the typical XRD pattern for the as-prepared nanoparticles is identical to the singlephase $\mathrm{CuO}$ with a monoclinic structure from the standard card JCPDS 72-0629 (Chen et al. 2012).

\section{Catalytic reaction experiment procedure}

Batch tests were carried out in aqueous solution at room temperature. Cupric oxide nanoparticles and phenol solution were added into the water in sequence, the final solution volumes were $25 \mathrm{ml}$. The reactions were initiated by adding $\mathrm{H}_{2} \mathrm{O}_{2}$ to a final concentration of $100 \mathrm{mM}$. At each checkpoint, the sample solution taken from the reaction batch was centrifuged to separate cupric oxide 
nanoparticles from solution. The phenol concentration was determined based on Emerson's method. The supernatant was mixed with $200 \mu \mathrm{l}$ ammonia buffer $(\mathrm{pH}=9.8), 20 \mu \mathrm{l}$ 4-aminoantipyrine solution ( $2 \%)$, and $20 \mu \mathrm{l}$ potassium ferricyanide solution $(8 \%)$, and then diluted to a final solution volume of $4.0 \mathrm{ml}$. After incubated for $10 \mathrm{~min}$, the absorbance at $510 \mathrm{~nm}$ was recorded using Shimadzu UV2450 spectrophotometer.

Analysis of the degradation intermediates

The degradation intermediates of phenol were determined with HPLC. The chromatographic conditions were as follows: C18 column $(4.6 \mathrm{~mm} \times 150 \mathrm{~mm})$; samples were injected into a $20 \mu \mathrm{l}$ loop; mobile phase was methanolwater containing $5 \% \mathrm{H}_{3} \mathrm{PO}_{4}$ (10:90) with a flow rate of $1 \mathrm{ml} / \mathrm{min}$. UV detector wavelength was set at 280 and $215 \mathrm{~nm}$.

\section{Results and discussion}

Catalytic degradation of phenol by cupric oxide nanoparticles

The effect of catalyst was investigated at room temperature and an initial phenol concentration of $0.25 \mathrm{~g} / \mathrm{l}$. The homogeneous reaction in the absence of catalyst is pronounced. Still, as shown in Fig. 1, the presence of the cupric oxide nanoparticles significantly enhances the oxidation rate of phenol in the reaction. In addition, it is clearly demonstrated that the degradation rate of phenol was improved by the increase in the concentration of cupric oxide nanoparticles. Complete removal of phenol can be

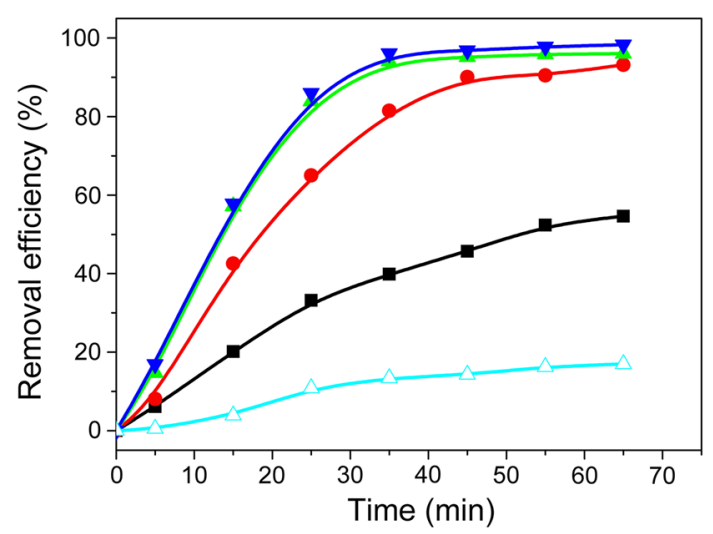

Fig. 1 Effect of the concentration of cupric oxide nanoparticles on removal efficiency of phenol. The concentration of phenol and $\mathrm{H}_{2} \mathrm{O}_{2}$ are $0.25 \mathrm{~g} / \mathrm{l}$ and $100 \mathrm{mM}$, respectively. The concentration of cupric oxide nanoparticles (mg/ml): (open triangle) 0 , (filled square) 0.001 , (filled circle) 0.01, (filled triangle) 0.03 , (inverted filled triangle) 0.05
Table 1 Removal efficiency of phenol in the presence of peroxidase nanomimics

\begin{tabular}{|c|c|c|c|c|c|}
\hline Catalyst (g/l) & $\mathrm{pH}$ & $\begin{array}{l}\text { Phenol/ } \\
\mathrm{H}_{2} \mathrm{O}_{2} \\
(\mathrm{ppm} / \\
\mathrm{mM})\end{array}$ & Time & $\begin{array}{l}\text { Removal } \\
\text { efficiency }\end{array}$ & Reference \\
\hline $\begin{array}{c}\mathrm{Au} / \mathrm{HAP} \\
(0.1)\end{array}$ & 6.8 & $100 / 490$ & $2 \mathrm{~h}$ & $82 \%$ & $\begin{array}{c}\text { Han et al. } \\
\text { (2008) }\end{array}$ \\
\hline $\begin{array}{l}\mathrm{Fe}_{3} \mathrm{O}_{4} \mathrm{NPs} \\
\quad(5)\end{array}$ & $6-7$ & $94 / 1,200$ & $6 \mathrm{~h}$ & $\sim 100 \%$ & $\begin{array}{l}\text { Zhang et al. } \\
\text { (2009) }\end{array}$ \\
\hline $\begin{array}{c}\mathrm{Fe}_{3} \mathrm{O}_{4} \mathrm{NPs} \\
(0.1)\end{array}$ & 3.0 & $282 / 6$ & $3 \mathrm{~h}$ & $\sim 85 \%$ & $\begin{array}{l}\text { Zhang et al. } \\
(2008)\end{array}$ \\
\hline $\begin{array}{l}\gamma \text {-FeOOH } \\
\text { nanosheets } \\
(0.12)\end{array}$ & & $40 / 500$ & $1 \mathrm{~h}$ & $\sim 80 \%$ & $\begin{array}{l}\text { Peng et al. } \\
\text { (2011) }\end{array}$ \\
\hline $\begin{array}{l}\operatorname{Iron}(3) \\
\text { oxide-based } \\
\text { NPs }(0.015)\end{array}$ & $2-3$ & $1,000 / 163$ & $0.5 \mathrm{~h}$ & $\sim 100 \%$ & $\begin{array}{l}\text { Zelmanov } \\
\text { and } \\
\text { Semiat } \\
(2008)\end{array}$ \\
\hline $\begin{array}{c}\mathrm{CuO} \text { NPs } \\
(0.05)\end{array}$ & $3-7$ & $250 / 100$ & $35 \mathrm{~min}$ & $\sim 100 \%$ & This work \\
\hline
\end{tabular}

achieved within 35 min when the concentration of cupric oxide nanoparticles exceeds $0.05 \mathrm{~g} / \mathrm{l}$. The experimental results show that this process is highly efficient as compared to that using other peroxidase nanomimics (Table 1).

To rule out the possibility that the observed catalytic activity is caused by copper ions leaching from cupric oxide nanoparticles in the solution, the reaction was conducted by using copper ions instead of cupric oxide nanoparticles. Even with the concentration of $0.625 \mathrm{mM}$ (equivalent quantity to $0.05 \mathrm{~g} / \mathrm{l}$ cupric oxide nanoparticles), copper ions have little effect on the reaction. The removal efficiency is about $32 \%$ in $35 \mathrm{~min}$ in this case. These experimental results reveal that the observed catalytic activity is due to intact nanoparticles.

Studies performed by employing nanomaterials determined that the size of the catalytic species has a considerable effect on the catalyst performance (Zhou et al. 2006). Our further investigation reveals that the catalytic activity of cupric oxide nanoparticles is size-dependent. The removal efficiency of phenol is only about $27.9 \%$ in $35 \mathrm{~min}$ even when 60 -folds cupric oxide nanoparticles $(3 \mathrm{mg} / \mathrm{ml})$ with the diameter of $30 \mathrm{~nm}$ were used.

Effect of the initial solution $\mathrm{pH}$

From the practical point of view, $\mathrm{pH}$ is one of the most important parameters influencing heterogeneous liquid phase catalytic oxidation of phenol (Rokhina and Virkutyte 2011). In batch experiments, the effect of initial $\mathrm{pH}$ on removal efficiency of phenol was examined in the range from 2 to 13. It was shown in Fig. 2 that most of the phenol 


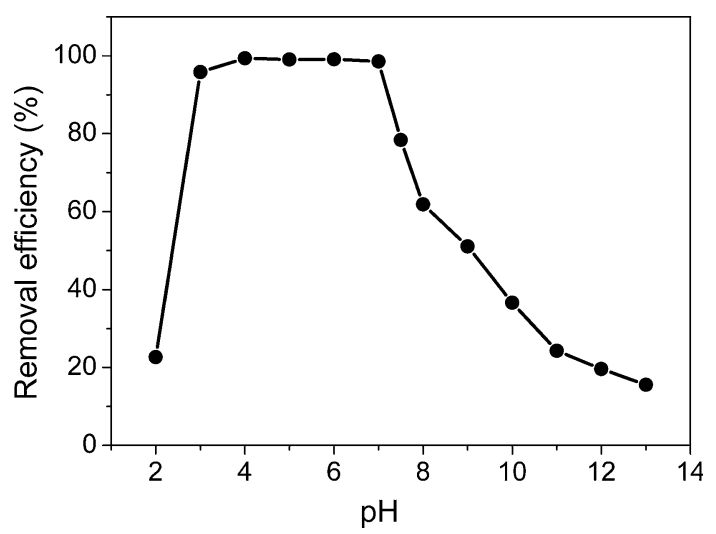

Fig. 2 Effect of initial solution $\mathrm{pH}$ on removal efficiency of phenol $\left(0.25 \mathrm{~g} / \mathrm{l}\right.$ phenol, $100 \mathrm{mM} \mathrm{H}_{2} \mathrm{O}_{2}, 0.05 \mathrm{~g} / \mathrm{l}$ cupric oxide nanoparticles, $35 \mathrm{~min})$

was removed under acidic and neutral conditions, and the removal efficiency was low at alkaline conditions. The removal efficiency of phenol in 35 min was about $100 \%$ under acidic and neutral conditions, and when $\mathrm{pH}$ above 7 , the removal efficiency decreased sharply until to about $15 \%$ at $\mathrm{pH} 13$. It can be explained by the decomposition of hydrogen peroxide in alkaline solution to produce molecular oxygen instead of formation of appreciable amounts of hydroxyl radicals (Guo and Al-Dahhan 2003). High pH also favors the formation of carbonate ions, which are effective scavengers of hydroxyl ions and therefore can reduce the degradation efficiency (Kashif and Ouyang 2009). Moreover, the combination of $\mathrm{OH}^{-}$with $\mathrm{Cu}^{2+}$ on the surface of the nanoparticles might inhibit the adsorption of hydrogen peroxide, and in turn negatively affecting the generation of hydroxyl radicals. The significant decline in the removal efficiency in strong acidic condition $(\mathrm{pH}<2)$ can be attributed to the decomposition of cupric oxide nanoparticles (Chen et al. 2012). This can be confirmed by the low catalytic activity of copper ions mentioned above.

\section{Effect of $\mathrm{H}_{2} \mathrm{O}_{2}$ concentration}

Hydrogen peroxide is often the oxidant choice for chemical oxidation because of its simplicity of operation and the innocuous nature of its byproduct, water (Rokhina and Virkutyte 2011). Coupled with a sufficient catalyst, hydrogen peroxide exhibits excellent reactivity and high utilization efficiency. To test whether the catalytic activity of the cupric oxide nanoparticles is, like the conventional enzyme HRP, dependent on the concentration of $\mathrm{H}_{2} \mathrm{O}_{2}$, time dependence of phenol conversion at different $\mathrm{H}_{2} \mathrm{O}_{2}$ concentrations was performed. As shown in Fig. 3, the concentration of phenol did not change in the absence of $\mathrm{H}_{2} \mathrm{O}_{2}$, which suggests that $\mathrm{H}_{2} \mathrm{O}_{2}$ is necessary in phenol degradation system. In addition, a trace amount of oxygen dissolved in water or potential dissociation of phenol due to adsorption does not have any contribution to the conversion of phenol under the reaction conditions. Higher initial removal rate and degradation efficiency result from a

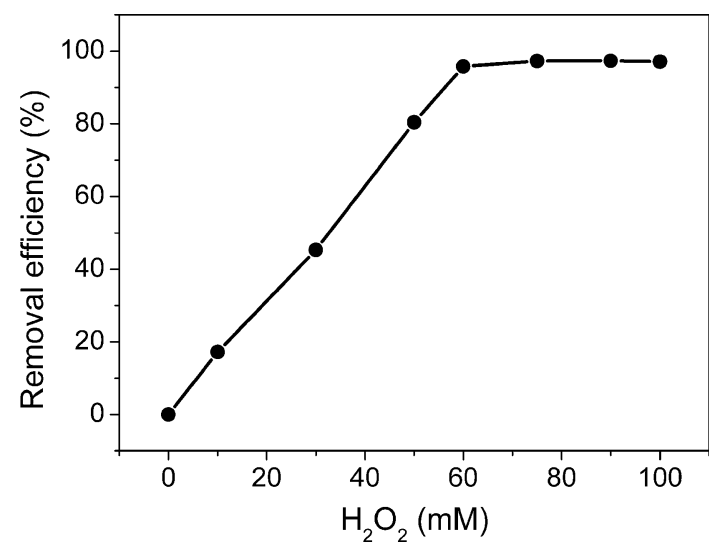

Fig. 3 Effect of the concentration of $\mathrm{H}_{2} \mathrm{O}_{2}$ on removal efficiency of phenol $(0.25 \mathrm{~g} / \mathrm{l}$ phenol, $0.05 \mathrm{~g} / \mathrm{l}$ cupric oxide nanoparticles, $35 \mathrm{~min})$
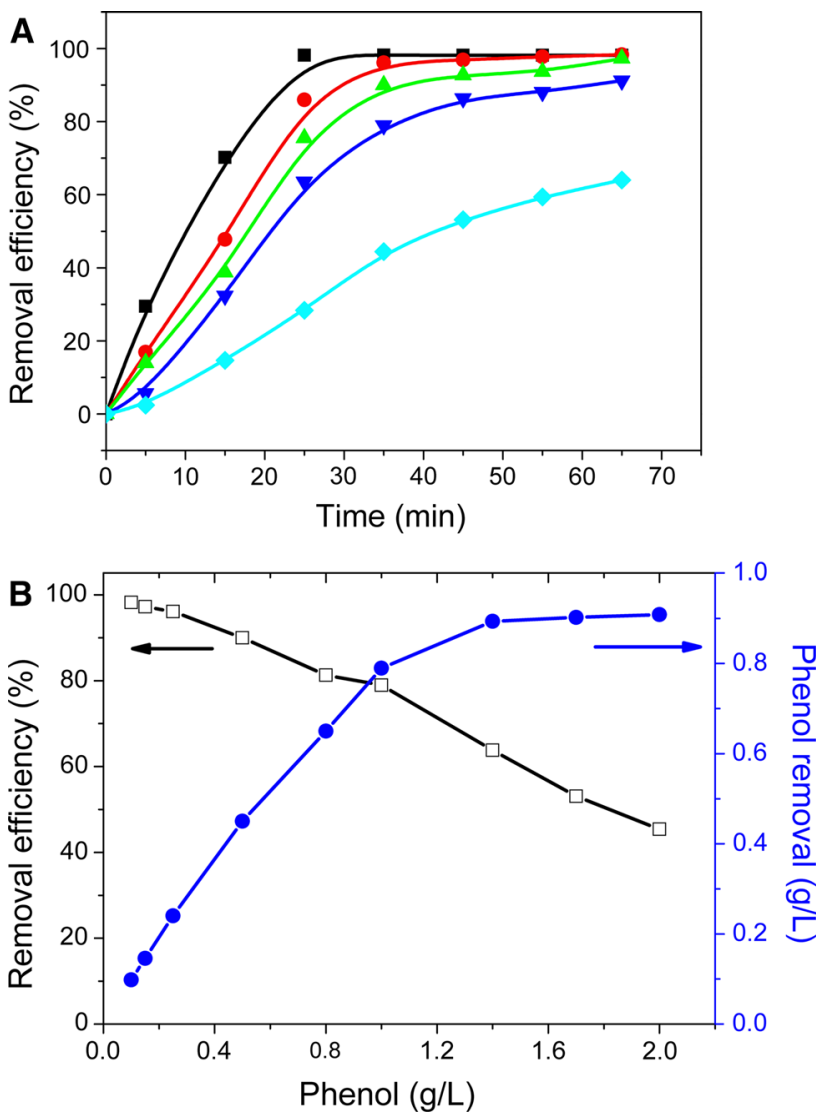

Fig. 4 a Degradation curves of phenol with different initial concentration $(\mathrm{g} / \mathrm{l})$. (filled square) 0.1 , (filled circle) 0.25 , (filled triangle) 0.5 , (inverted filled triangle) 1, (filled diamond) 2. b Plot of phenol removal efficiency at $35 \mathrm{~min}$ versus initial concentration of phenol (100 mM H $\mathrm{H}_{2} \mathrm{O}_{2}, 0.05 \mathrm{~g} / \mathrm{l}$ cupric oxide nanoparticles, $35 \mathrm{~min}$ ) 
higher $\mathrm{H}_{2} \mathrm{O}_{2}$ concentration. To reach the maximal level of phenol removal in $35 \mathrm{~min}, 60 \mathrm{mM} \mathrm{H} \mathrm{H}_{2} \mathrm{O}_{2}$ was required.

Effect of phenol concentration

The effect of the initial concentration of phenol was investigated in the range of 0.1-2 g/l. As shown in Fig. 4, the removal efficiency at $35 \mathrm{~min}$ was decreased with the increasing initial concentration of phenol. It took with 25 , 35 and 65 min to totally destroy phenol with the initial concentration of $0.1,0.25$ and $0.5 \mathrm{~g} / \mathrm{l}$, respectively. It has been reported that high concentrations of organic pollutants usually inhibit free radical formation in the wet peroxide oxidation process (Kurian and Sugunan 2006). However, the conversion amount and the degradation rate are both proportional to the initial concentration of phenol in the range of $0.1-1 \mathrm{~g} / \mathrm{l}$, indicating that the inhibition of free radicals can be ignored in this case. When the initial concentration of phenol exceeds $1 \mathrm{~g} / \mathrm{l}$, the relative activity of the catalyst indeed decreased. It takes much longer to remove phenol when the solution is more concentrated. As for $2 \mathrm{~g} / \mathrm{l}$ phenol solution, $80 \%$ degradation can only be achieved after $4 \mathrm{~h}$ in presence of $100 \mathrm{mM} \mathrm{H}_{2} \mathrm{O}_{2}$. Since $\mathrm{H}_{2} \mathrm{O}_{2}$ is the origin of the hydroxyl radicals, higher degradation rate can be expected in the presence of sufficient amount of hydrogen peroxide. Over 78 and $90 \%$ phenol can be successfully removed within $35 \mathrm{~min}$ for $2 \mathrm{~g} / \mathrm{l}$ phenol solution in the presence of 200 and $400 \mathrm{mM} \mathrm{H}_{2} \mathrm{O}_{2}$, respectively.

\section{Possible reaction mechanism}

Under the typical reaction conditions as described in experimental section, control teats were implemented in the case of phenol oxidation. There is almost no conversion of phenol in the absence of both cupric oxide nanoparticles and $\mathrm{H}_{2} \mathrm{O}_{2}$ after incubation for $65 \mathrm{~min}$. Also, under the similar conditions in a $\mathrm{H}_{2} \mathrm{O}_{2}$-free solution, phenol was not

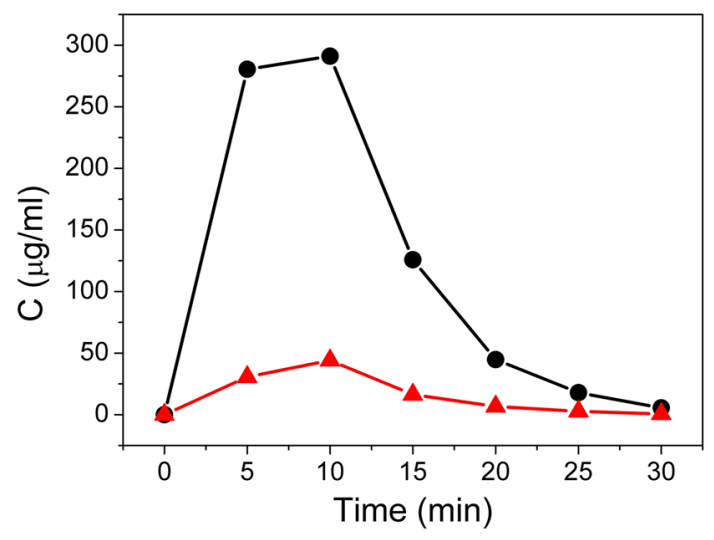

Fig. 6 Concentration variation of (filled circle) catechol and (filled triangle) hydroquinone in the degradation process of phenol

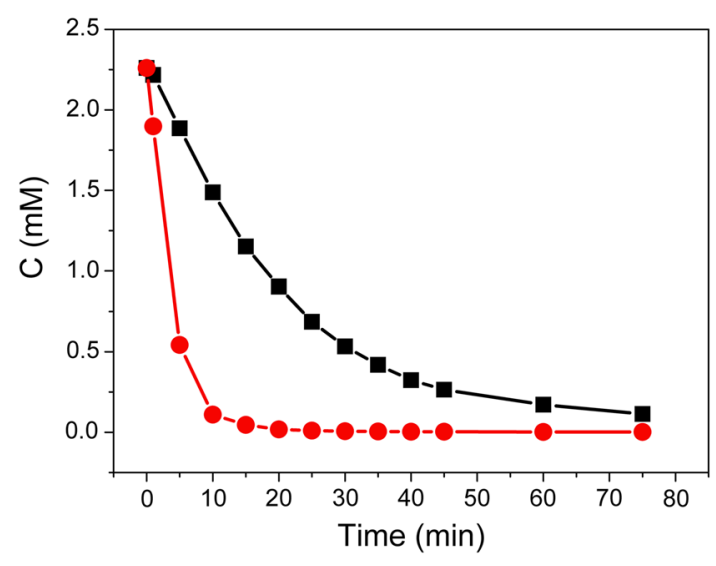

Fig. 7 Degradation curve of (filled square) catechol and (filled circle) hydroquinone (100 $\mathrm{mM} \mathrm{H}_{2} \mathrm{O}_{2}, 0.05 \mathrm{~g} / \mathrm{l}$ cupric oxide nanoparticles)
Fig. 5 Chromatograms of the degradation solution of phenol

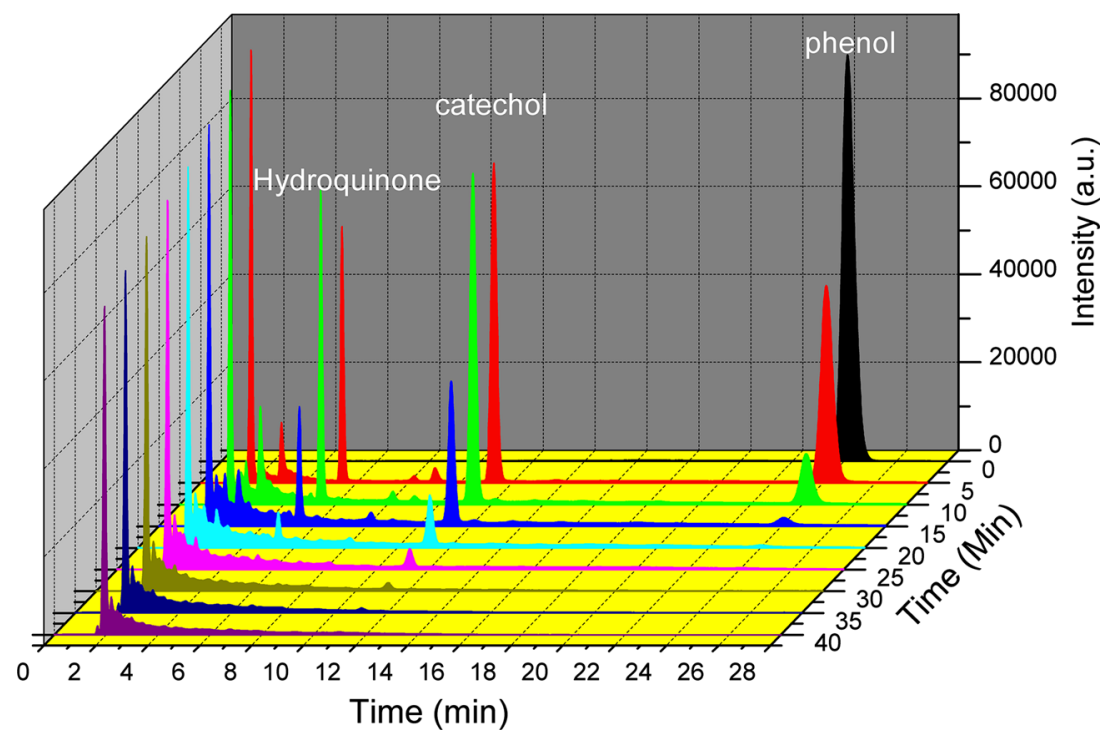




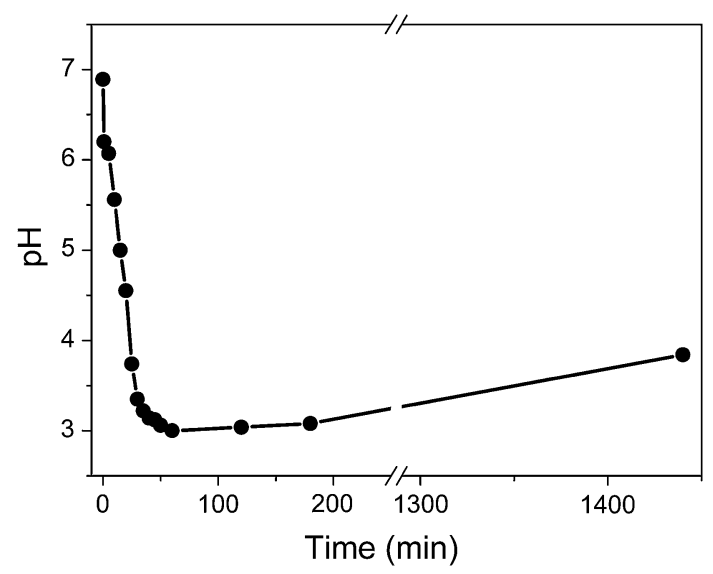

Fig. $8 \mathrm{pH}$ change along the degradation reaction of phenol

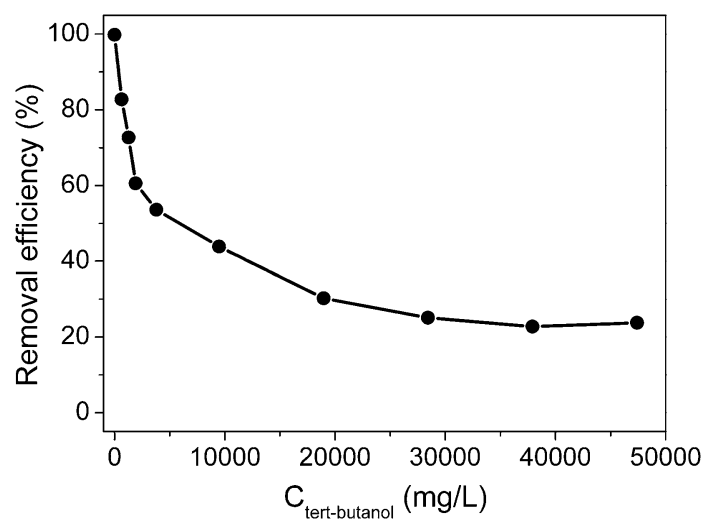

Fig. 9 Influence of tert-butanol on removal efficiency of phenol ( $0.25 \mathrm{~g} / \mathrm{l}$ phenol, $100 \mathrm{mM} \mathrm{H}_{2} \mathrm{O}_{2}, 0.05 \mathrm{~g} / \mathrm{l}$ cupric oxide nanoparticles, $35 \mathrm{~min})$

converted. In the case of without cupric oxide nanoparticles in the reaction solution, only $16.4 \%$ of phenol was removed. These results suggest that adsorption by cupric oxide nanoparticles and direct oxidation by $\mathrm{H}_{2} \mathrm{O}_{2}$ or dissolved oxygen do not mainly contribute to the removal of phenol under reaction conditions. So the loss of phenol was caused mainly by catalytic oxidation of cupric oxide nanoparticles in the presence of $\mathrm{H}_{2} \mathrm{O}_{2}$.

In order to investigate degradation intermediates of phenol, the reaction solution was analyzed by HPLC. The main detected intermediates in the product effluent were hydroquinone, catechol, maleic acid, and oxalic acid. For the existence of mineralization and intermediates detected, the degradation of phenol could be divided into two stages (Rokhina and Virkutyte 2011). During the first stage, hydroxylation of aromatic ring and formation of dihydroxybenzenes such as hydroquinone and catechol are observed. The existence of maximum points for hydroquinone and catechol can be observed in Figs. 5, 6. These profiles exhibit a common characteristic of the consecutive reaction pathway in which hydroquinone and catechol are formed from phenol and degraded progressively to simpler compounds. The degradation of hydroquinone and catechol in the presence of cupric oxide nanoparticles were further proved by using hydroquinone and catechol as initial reactants (Fig. 7). In the second oxidation stage, the aromatic rings open to form carboxyl acids. Similar to dihydroxybenzenes, the existence of maximum points for carboxyl acids can also be observed, indicating that they are further oxidized to water and carbon dioxide. After $35 \mathrm{~min}$, phenol, hydroquinone, and catechol are completely degraded. Only small amount of oxalic acid can be detected in the solution.

Obvious $\mathrm{pH}$ change can be observed along the reaction. As shown in Fig. 8, in the initial stage, the $\mathrm{pH}$ value decreased rapidly to about 3 , which can be contributed to the formation of acidic intermediates. Then in the next stage, the $\mathrm{pH}$ value of the reaction system increased slowly to 3.9 , which is consistent with that of carbon dioxide saturated solution.

To confirm the existence of hydroxyl free radical, tertbutanol was introduced into the reaction system. As a strong radical scavenger, tert-butanol remarkably decreased the removal efficiency of phenol (Fig. 9). The results suggested that cupric oxide nanoparticles could catalyze $\mathrm{H}_{2} \mathrm{O}_{2}$ to form hydroxyl free radicals, which were mainly responsible for the removal of phenol.

Application in the treatment of waste water from ink production

The proposed method was applied for the degradation of phenol in waste water from ink production. The initial concentration of phenol in the samples was in the range of $0.1-0.5 \mathrm{~g} / \mathrm{l}$. The experimental results show that over $90 \%$ phenol can be successfully removed within $1 \mathrm{~h}$ in the presence of $400 \mathrm{mM} \mathrm{H}_{2} \mathrm{O}_{2}$ and $0.05 \mathrm{~g} / \mathrm{l}$ cupric oxide nanoparticles.

\section{Conclusion}

As a kind of peroxidase mimetic substance, cupric oxide nanoparticles can be used as a promising catalyst for the total oxidation of phenol in aqueous solutions by peroxidation, which therefore avoids the need of secondary treatments. High degradation efficiency of phenol can be achieved in relatively wide $\mathrm{pH}$ range from 3 to 7 . Under optimized conditions, phenol can be eliminated completely in a short period. It can be potentially applied in treating the industrial wastewaters.

Acknowledgments We acknowledge the financial support of the National Natural Science Foundation of China (21175023), the 
Natural Science Foundation of Fujian Province (2011J01034, 2012J06019), Science and Technology Planning Project of Fujian Province (2011Y0030), and the Program for New Century Excellent Talents in Fujian Province University (JA11102).

\section{References}

Barrault J, Abdellaoui M, Bouchoule C, Majeste A, Tatibouet JM, Louloudi A, Papayannakos N, Gangas NH (2000) Catalytic wet peroxide oxidation over mixed (al-fe) pillared clays. Appl Catal B Environ 27(4):L225-L230

Bornscheuer UT (2003) Immobilizing enzymes: how to create more suitable biocatalysts. Angew Chem Int Ed 42(29):3336-3337

Burleigh MC, Markowitz MA, Spector MS, Gaber BP (2002) Porous polysilsesquioxanes for the adsorption of phenols. Environ Sci Technol 36(11):2515-2518

Calleja G, Melero JA, Martinez F, Molina R (2005) Activity and resistance of iron-containing amorphous, zeolitic and mesostructured materials for wet peroxide oxidation of phenol. Water Res 39(9):1741-1750

Chedeville O, Debaccq M, Almanza MFA, Porte C (2007) Use of an ejector for phenol containing water treatment by ozonation. Sep Purif Technol 57(2):201-208

Chen H, Sayari A, Adnot A, Larachi F (2001) Composition-activity effects of Mn-Ce-O composites on phenol catalytic wet oxidation. Appl Catal B Environ 32(3):195-204

Chen W, Chen J, Liu AL, Wang LM, Li GW, Lin XH (2011) Peroxidase-like activity of cupric oxide nanoparticle. Chemcatchem 3(7):1151-1154

Chen W, Chen J, Feng YB, Hong L, Chen QY, Wu LF, Lin XH, Xia XH (2012) Peroxidase-like activity of water-soluble cupric oxide nanoparticles and its analytical application for detection of hydrogen peroxide and glucose. Analyst 137(7):1706-1712

Cheng J, Yu SM, Zuo P (2006) Horseradish peroxidase immobilized on aluminum-pillared interlayered clay for the catalytic oxidation of phenolic wastewater. Water Res 40(2):283-290

Dabrowski A, Podkoscielny P, Hubicki Z, Barczak M (2005) Adsorption of phenolic compounds by activated carbon - a critical review. Chemosphere 58(8):1049-1070

Dileo GJ, Neff ME, Savage PE (2007) Gasification of guaiacol and phenol in supercritical water. Energy Fuels 21(4):2340-2345

Duran N, Esposito E (2000) Potential applications of oxidative enzymes and phenoloxidase-like compounds in wastewater and soil treatment: a review. Appl Catal B Environ 28(2):83-99

Gao LZ, Zhuang J, Nie L, Zhang JB, Zhang Y, Gu N, Wang TH, Feng J, Yang DL, Perrett S, Yan X (2007) Intrinsic peroxidase-like activity of ferromagnetic nanoparticles. Nat Nanotechnol 2(9):577-583

Gonzalez PS, Agostini E, Milrad SR (2008) Comparison of the removal of 2,4-dichlorophenol and phenol from polluted water, by peroxidases from tomato hairy roots, and protective effect of polyethylene glycol. Chemosphere 70(6):982-989

Guo J, Al-Dahhan M (2003) Catalytic wet oxidation of phenol by hydrogen peroxide over pillared clay catalyst. Indust Eng Chem Res 42(12):2450-2460

Han YF, Phonthammachai N, Ramesh K, Zhong Z, White T (2008) Removing organic compounds from aqueous medium via wet peroxidation by gold catalysts. Environ Sci Technol 42(3):908-912

Hoshi M, Kogure M, Saitoh T, Nakagawa T (1997) Separation of aqueous phenol through polyurethane membranes by pervaporation. J Appl Polym Sci 65(3):469-479
Jiang HL, Tay JH, Maszenan AM, Tay STL (2006) Enhanced phenol biodegradation and aerobic granulation by two coaggregating bacterial strains. Environ Sci Technol 40(19):6137-6142

Joglekar HS, Samant SD, Joshi JB (1991) Kinetics of wet air oxidation of phenol and substituted phenols. Water Res 25(2):135-145

Kang N, Lee DS, Yoon J (2002) Kinetic modeling of fenton oxidation of phenol and monochlorophenols. Chemosphere 47(9):915-924

Kashif N, Ouyang F (2009) Parameters effect on heterogeneous photocatalysed degradation of phenol in aqueous dispersion of $\mathrm{TiO}_{2}$. J Environ Sci 21(4):527-533

Klibanov AM, Tu TM, Scott KP (1983) Peroxidase-catalyzed removal of phenols from coal-conversion waste-waters. Science 221(4607):259-260

Kurian M, Sugunan S (2006) Tert-butylation of phenol catalysed by metal exchanged iron pillared montmorillonites. Catal Commun 7(6):417-421

Li Z, Wu MH, Jiao Z, Bao BR, Lu SL (2004) Extraction of phenol from wastewater by n-octanoylpyrrolidine. J Hazard Mater 114(1-3):111-114

Li XY, Cui YH, Feng YJ, Xie ZM, Gu JD (2005) Reaction pathways and mechanisms of the electrochemical degradation of phenol on different electrodes. Water Res 39(10):1972-1981

Liu YJ, Jiang XZ (2005) Phenol degradation by a nonpulsed diaphragm glow discharge in an aqueous solution. Environ Sci Technol 39(21):8512-8517

Lu DL, Shao GC, Du D, Wang J, Wang LM, Wang WJ, Lin YH (2011) Enzyme entrapped nanoporous scaffolds formed through flow-induced gelation in a microfluidic filter device for sensitive biosensing of organophosphorus compounds. Lab Chip 11(3):381-384

Pacheco MJ, Morao A, Lopes A, Ciriaco L, Goncalves I (2007) Degradation of phenols using boron-doped diamond electrodes: a method for quantifying the extent of combustion. Electrochim Acta 53(2):629-636

Peng C, Jiang BW, Liu Q, Guo Z, Xu ZJ, Huang Q, Xu HJ, Tai RZ, Fan CH (2011) Graphene-templated formation of two-dimensional lepidocrocite nanostructures for high-efficiency catalytic degradation of phenols. Energy Environ Sci 4(6):2035-2040

Rokhina EV, Virkutyte J (2011) Environmental application of catalytic processes: heterogeneous liquid phase oxidation of phenol with hydrogen peroxide. Crit Rev Environ Sci Technol 41(2):125-167

Schmid A, Dordick JS, Hauer B, Kiener A, Wubbolts M, Witholt B (2001) Industrial biocatalysis today and tomorrow. Nature 409(6817):258-268

Schoemaker HE, Mink D, Wubbolts MG (2003) Dispelling the mythsbiocatalysis in industrial synthesis. Science 299(5613):1694-1697

Ucun H, Yildiz E, Nuhoglu A (2010) Phenol biodegradation in a batch jet loop bioreactor (JLB): kinetics study and ph variation. Bioresour Technol 101(9):2965-2971

Vione D, Minero C, Maurino V, Carlotti AE, Picatonotto T, Pelizzetti $\mathrm{E}$ (2005) Degradation of phenol and benzoic acid in the presence of a $\mathrm{TiO}_{2}$-based heterogeneous photocatalyst. Appl Catal B Environ 58(1-2):79-88

Wang ZP, Cai WM, Hong XT, Zhao XL, Xu F, Cai CG (2005) Photocatalytic degradation of phenol in aqueous nitrogen-doped $\mathrm{TiO}_{2}$ suspensions with various light sources. Appl Catal B Environ 57(3):223-231

Zelmanov G, Semiat R (2008) Iron(3) oxide-based nanoparticles as catalysts in advanced organic aqueous oxidation. Water Res 42(1-2):492-498

Zhang JB, Zhuang J, Gao LZ, Zhang Y, Gu N, Feng J, Yang DL, Zhu JD, Yan XY (2008) Decomposing phenol by the hidden talent of ferromagnetic nanoparticles. Chemosphere 73(9):1524-1528 
Zhang SX, Zhao XL, Niu HY, Shi YL, Cai YQ, Jiang GB (2009) Superparamagnetic $\mathrm{Fe}_{3} \mathrm{O}_{4}$ nanoparticles as catalysts for the catalytic oxidation of phenolic and aniline compounds. J Hazard Mater 167(1-3):560-566
Zhou CH, Tong DS, Bao M, Du ZX, Ge ZH, Li XN (2006) Generation and characterization of catalytic nanocomposite materials of highly isolated iron nanoparticles dispersed in clays. Topics in Catal 39(3-4):213-219 